Research Article

\title{
Bearing Capacities of Different-Diameter Concrete-Filled Steel Tubes under Axial Compression
}

\author{
Wenjing Wang, Zhenyun Tang, Zhenbao Li, and Hua Ma \\ Beijing University of Technology, Key Laboratory of Urban Security and Disaster Engineering of Education Ministry, Beijing, China \\ Correspondence should be addressed to Zhenbao Li; lizb@bjut.edu.cn
}

Received 15 July 2016; Revised 23 October 2016; Accepted 24 November 2016

Academic Editor: Stevulova Nadezda

Copyright (C) 2016 Wenjing Wang et al. This is an open access article distributed under the Creative Commons Attribution License, which permits unrestricted use, distribution, and reproduction in any medium, provided the original work is properly cited.

\begin{abstract}
The bearing capacities of concrete-filled steel tubes are normally derived through experiments with small-scale specimens, but it is uncertain whether such derivations are appropriate for the much larger components used in practical engineering. This study therefore investigates the effect of different diameters $(219,426,630$, and $820 \mathrm{~mm})$ on the axial compression of short concrete columns in steel (Q235) tubes. It is found that the peak nominal stress decreases with increasing specimen size and that the axial bearing capacity is determined by three separate components: the cylinder compressive strength of the concrete, the improvement in strength due to the confining effect of the steel tube, and the longitudinal strength of the steel tube. At peak load, increases in the specimen diameter reduce the hoop stresses in the steel tube, thereby reducing the strengthening effect of confinement. Vertical stress in the steel tube is increased with diameter; therefore, the axial bearing capacity of the steel tube is directly related to the specimen size. Size effect coefficients for these three aspects of bearing capacity are defined and used to develop a size-dependent model for predicting the axial bearing capacity of large, concrete-filled steel tubes. The model is then validated against experimental data.
\end{abstract}

\section{Introduction}

Although it is possible with concrete-filled steel tubes (CFTs) to improve the capacity of the concrete core and delay localized buckling of the steel tube, previous studies [1] on the mechanical behavior of CFTs have examined small (100-200 mm diameter) specimens because of the limitations of available testing facilities. Current design codes for CFT structures (e.g., GB50936-2014 [2], AIJ-2008 [3], and ANSI/AISC 360-10 [4]) also do not consider possible size effect. Consequently, doubt remains regarding the application of values extrapolated linearly from experimental data to larger-size components in engineering design. It is important to understand the size effect regarding the axial bearing capacity of CFTs.

Research into the size effect of concrete materials began in the 1920s, with Blanks and McNamara [5] demonstrating that the cylinder compressive strength of concrete was decreased with increasing diameter. Noguchi and Tomosawa [6] later proposed a formula to calculate the cylinder compressive strength of concrete that considered the cylinder size, based on statistical Weibull theory. Bažant and Xiang [7] also proposed a size effect law (SEL) for the compressive strength of concrete based on the buckling theory of internal microslabs. Using this, Kim et al. [8] established a modified SEL specifically for concrete cylinders based on a substantial amount of experimental data. These studies have validated the SEL for the cylinder compressive strength of concrete.

Despite these efforts, research on the size effect of confined concrete did not begin until the 1990s. At this time, Kim et al. [8] used existing experimental data for spirally reinforced concrete under axial compression to determine that the strength of confined concrete was decreased with increases in specimen diameter, when the confining stress was small. Li et al. $[9,10]$ subsequently tested a series of concrete specimens confined by circular or square lateral steel reinforcement with a maximum diameter of $800 \mathrm{~mm}$ to obtain an SEL that predicted the compressive strength of confined concrete. This model considered the size effect in relation to not only the material properties of concrete, but also the strength produced by the confinement effect of lateral steel. Wang and $\mathrm{Wu}[11]$ also conducted axial compression 
experiments for aramid fiber-reinforced polymer- (AFRP-) confined concrete with different diameters; based on these, they proposed a modified variant of Bažant and Xiang's SEL [7] to consider the size effect on both the concrete material and confinement effect. Elkadi and van Mier [12] tested hollow concrete cylinders of different sizes under multiaxial compression and found that the triaxial compressive strength decreased with increasing size. It was also observed that the size effect was influenced by both the stress distribution and the concrete material. Thus, previous research on confined concrete has shown that size affects not only the concrete itself, but also any increase in strength provided by the confinement effect.

The size effect on CFT was investigated by Luksha and Nesterovich [13] through axial compression tests of short columns by varying the concrete strength and diameter-tothickness ratio within the diameter range of $159-1020 \mathrm{~mm}$. They found that small-scale specimens experienced plastic failure, whereas shear failure at different angles was observed in the larger-scale specimens. Yamamoto et al. [14], Chen et al. [15], and Tian [16] all found experimentally that the axial bearing capacity of circular CFT changed little with increasing size. Yamamoto et al. $[17,18]$ then proposed a constitutive model for circular CFT that utilized Noguchi and Tomosawa's size effect model [6] to modify the strength of the concrete material. Sakino et al. [19] fitted a size effect reduction factor for the compressive strength of a concrete cylinder based on the test data of Blanks and McNamara [5]. This reduction factor was subsequently adopted by Yamamoto et al. [20], Liang and Fragomeni [21], and Liang [22] to consider size when they established their respective CFT bearing capacity formulas. Caner and Bažant [23] used the data obtained through microplane model analysis and axial compression tests of CFT specimens with different diameter-to-thickness ratios to demonstrate that the critical steel ratio for size to have an effect was $4-8 \%$. Wu and Wang [24] processed existing bearing capacity data for circular CFT columns under axial compression and concluded that smaller degrees of lateral pressure on the concrete core correlated to greater significance of the size effect on the nominal stress. These past investigations show that the effect of varying the size of a CFT specimen remains uncertain, especially regarding the relationship between size and the confinement of the concrete core by the steel tube.

This study experimentally investigates the effect of diameter variations of circular CFT specimens between 219 and $820 \mathrm{~mm}$ on their axial bearing capacities. The size effect on the cylinder compressive strength of concrete, the steel tube stress, and the confinement of the concrete core by the steel tube are all discussed. Through the collected data, a sizedependent model for axial bearing capacity is developed.

\section{Experimental Procedure}

A total of four groups of eight CFT specimens were used. Each specimen was a circular column with a height-to-diameter ratio of 3 and nominal diameter-to-thickness ratio $(D / t)$ of 88 . The test parameter was the outer diameter of the specimen, set to $219,426,630$, or $820 \mathrm{~mm}$. The design details of the
TABLE 1: Specimen design details.

\begin{tabular}{lcccc}
\hline $\begin{array}{l}\text { Specimen } \\
\text { number }\end{array}$ & $\begin{array}{c}\text { Diameter } D \\
{[\mathrm{~mm}]}\end{array}$ & $\begin{array}{c}\text { Height } H \\
{[\mathrm{~mm}]}\end{array}$ & $\begin{array}{c}\text { Thickness of } \\
\text { steel tube } t \\
{[\mathrm{~mm}]}\end{array}$ & $D / t$ \\
\hline CD2-1 & 215.4 & 657 & 2.5 & 85.0 \\
CD2-2 & 216.6 & 657 & 2.5 & 86.6 \\
CD4-1 & 425.8 & 1278 & 5.2 & 82.4 \\
CD4-2 & 427.1 & 1278 & 5.1 & 83.8 \\
CD6-1 & 628.5 & 1890 & 6.9 & 91.1 \\
CD6-2 & 628.0 & 1890 & 7.1 & 88.0 \\
CD8-1 & 817.4 & 2460 & 9.0 & 90.8 \\
CD8-2 & 820.8 & 2460 & 9.3 & 87.9 \\
\hline
\end{tabular}

TABLE 2: Mechanical properties of steel tube.

\begin{tabular}{lccc}
\hline $\begin{array}{l}\text { Specimen } \\
\text { number }\end{array}$ & $\begin{array}{c}\text { Yield } \\
\text { strength } f_{y} \\
{[\mathrm{MPa}]}\end{array}$ & $\begin{array}{c}\text { Ultimate } \\
\text { strength } f_{u} \\
{[\mathrm{MPa}]}\end{array}$ & $\begin{array}{c}\text { Break } \\
\text { elongation } A \\
{[\%]}\end{array}$ \\
\hline CD2 & 590.4 & 619.5 & 3.7 \\
CD4 & 259.8 & 418.4 & 24.4 \\
CD6 & 276.0 & 437.9 & 29.1 \\
CD8 & 278.8 & 416.2 & 30.9 \\
\hline
\end{tabular}

specimens are given in Table 1. Each sample is named based on the following convention: $C$ represents a circular sample, $D$ is its diameter $(2,4,6$, or 8 for $219,426,630$, and $820 \mathrm{~mm}$, resp.), and the final number $(-1$ or -2$)$ denotes whether it is the first or the second specimen of the same dimensions.

Straight-seam steel pipe (grade Q235) was used for the $219 \mathrm{~mm}$ diameter specimens, while the other diameters used spiral pipes of the same steel grade. After welding a steel plate to the bottom of each pipe, the pipes were filled with pumping concrete containing aggregate with a maximum size of $25 \mathrm{~mm}$. Each specimen was cast vertically in layers in the same batch, along with cube- and prism-shaped blocks for determining the mechanical properties of the concrete. The concrete was then steam-cured and its surface was plastered, after which a second steel plate was welded to the top of the pipe. The surface of the pipe was painted white to provide protection against corrosion during specimen production and to facilitate observation during testing. Three steel samples were obtained from each type of tube in the vertical direction to determine the properties of the steel tube.

The mechanical properties of the steel and concrete used are listed in Tables 2 and 3, respectively, with all values obtained in accordance with Chinese Code GB-T 228.1-2010 and GB/T 50081-2002 [25, 26]. In Table 2, the strength of the steel tube used with CD2 is much higher than the others.

The CFT specimens were tested at the Key Laboratory of Urban Security and Disaster Engineering of the Education Ministry at the Beijing University of Technology. Here, a 40 $\mathrm{MN}$ multifunction electrohydraulic servo loading system was used to apply continuous and monotonic axial compression to the specimens. This loading device and the arrangement of measuring points used are depicted in Figure 1. A hybrid 


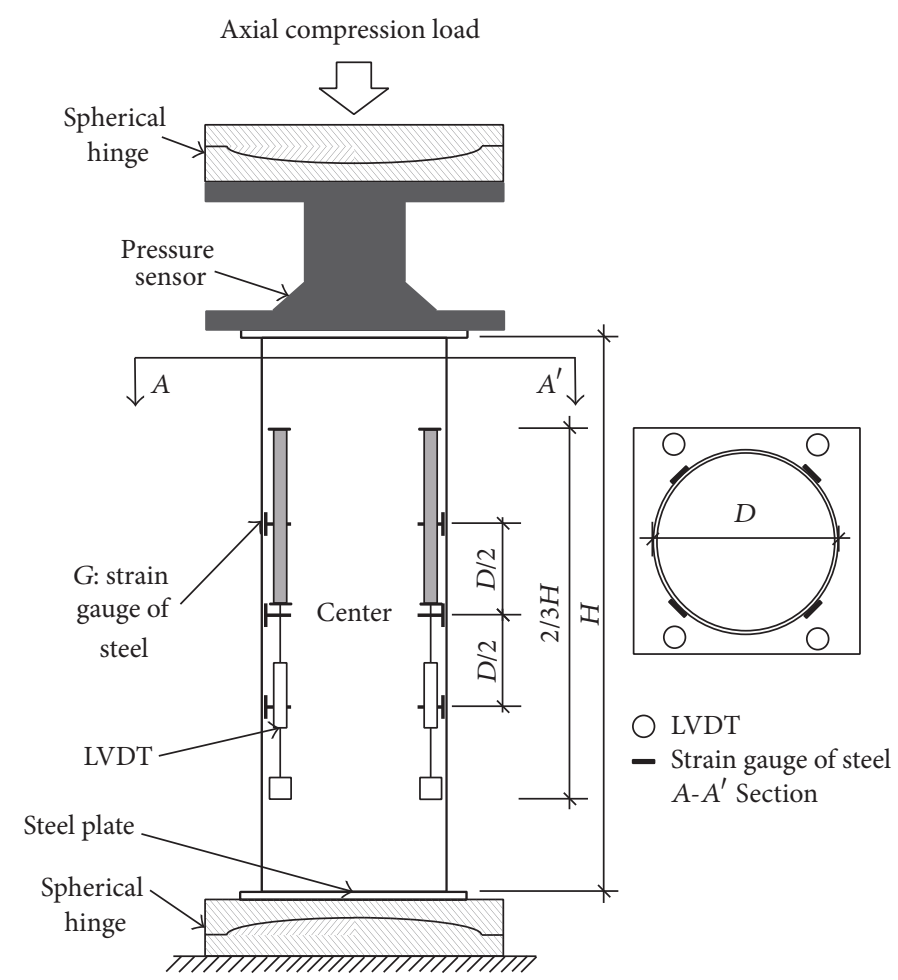

Figure 1: Test loading device and arrangement of measuring points.

TABLE 3: Mechanical properties and mixture ratio of concrete.

\begin{tabular}{lc}
\hline Prism compressive strength $f_{c}[\mathrm{MPa}]$ & 41.24 \\
Cube compressive strength $f_{\mathrm{cu}}[\mathrm{MPa}]$ & 51.51 \\
Cement $\left[\mathrm{kg} \cdot \mathrm{m}^{-3}\right]$ & 270 \\
Water $\left[\mathrm{kg} \cdot \mathrm{m}^{-3}\right]$ & 175 \\
Sand $\left[\mathrm{kg} \cdot \mathrm{m}^{-3}\right]$ & 865 \\
Stone $\left[\mathrm{kg} \cdot \mathrm{m}^{-3}\right]$ & 1015 \\
Admixtures $\left[\mathrm{kg} \cdot \mathrm{m}^{-3}\right]$ & 4.8 \\
Fly ash $\left[\mathrm{kg} \cdot \mathrm{m}^{-3}\right]$ & 67 \\
\hline
\end{tabular}

control of force and displacement was used with this loading system; force was controlled until the specimen reached $90 \%$ of its bearing capacity. Beyond this, the loading system switched to displacement control until the total deformation reached $6 \%$ of the specimen height, at which point the test loading was ended.

During loading, an IMP static data-acquisition system was used to record the axial load on the specimen, as measured by a force sensor. The axial deformation in the middle of the specimen was measured by four linear variable differential transformers (LVDTs) over two-thirds of the specimen height (i.e., $2 / 3 H$ ). The strain in the steel tube $(G)$ was recorded by vertical and horizontal strain gauges at each measuring point.

\section{Experimental Results}

3.1. Failure Mode. From the surface of each specimen at the time of peak loading, as shown in Figure 2, it is evident that all developed axial deformation with no evidence of oblique cracks. The final failure modes, displayed in Figure 3, indicate that all specimens experienced shear failure. The destruction of each specimen therefore appears to have followed the same process, with axial deformation gradually increasing with load up to the peak load value. Beyond this load, axial deformation was greatly accelerated, resulting in the peeling of the white paint and the formation of oblique fracture bands on the surface of the steel tube. These cracks gradually connected and extended though the specimen. This was accompanied by localized surface buckling and a continuous loss of bearing capacity, which eventually resulted in catastrophic damage.

3.2. Experimental Curves. The load-axial deformation curve for each specimen is presented in Figure 4, while the average stress-strain curves are displayed in Figure 5. Note that the average stress in Figure 5 represents the ratio of load to section area, while the strain in the ascending segment is the average strain of all gauging points at the surface of the steel tube. The strain in the declining segment, however, is the average strain of the four LVDTs with the gauge length of $2 / 3 H$, as calculated from the strain of each LVDT by dividing the gauge's axial deformation by the gauge length. Similarly, the axial deformation in Figure 4 was obtained by multiplying the strain in Figure 5 by the gauge length $(2 / 3 H)$. 


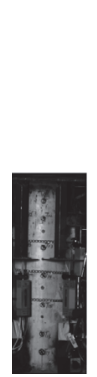

CD2-1

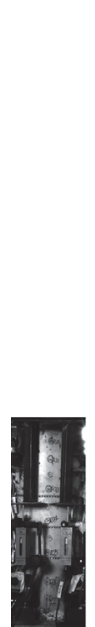

$\mathrm{CD} 2-2$

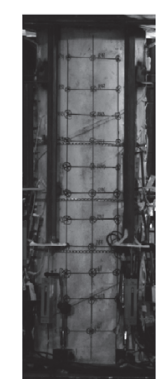

CD4-1

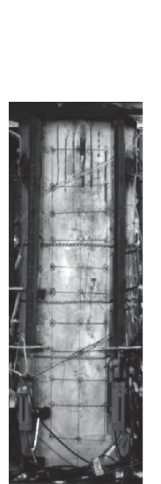

CD4-2

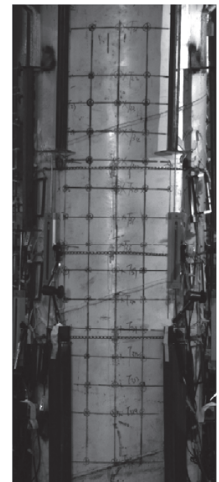

CD6-1

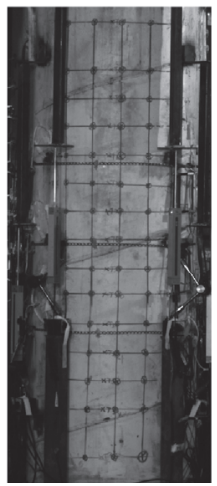

CD6-2

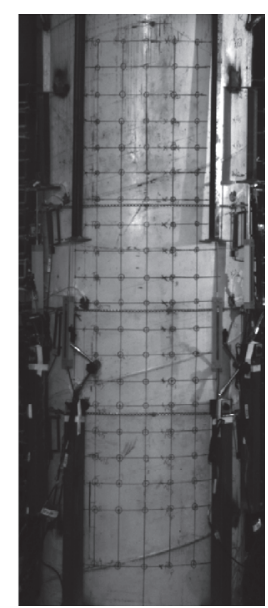

CD8-1

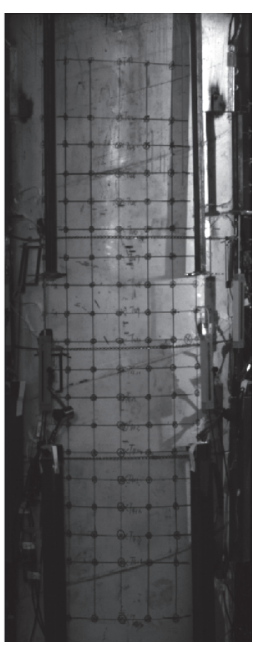

CD8-2

FIGURE 2: Appearance of each specimen at peak load.

The presence of falling sections with specimens of different diameters in Figures 4 and 5, rather than a plastic strain-hardening range, is consistent with the inherently brittle nature of concrete.

3.3. Ultimate Bearing Capacity and Stress. The main test results obtained at the peak bearing capacity of each specimen are listed in Table 4. In Table 4, the stress of the confined concrete $\left(f_{\text {cc_exp }}\right)$ was obtained based on the experimental results, as discussed in Section 4.3; $N_{u}$ was the computed axial capacity of CFT by the model proposed in Section 4. The relation between the peak average stress and the diameter of the specimen, as plotted in Figure 6, shows a gradual decrease in stress with increasing size up to a diameter of $630 \mathrm{~mm}$, beyond which the stress appears to remain constant.

\section{Size-Dependent Model of Axial Bearing Capacity}

4.1. Modeling. At the beginning of the loading of the CFT column, the Poisson ratio of concrete is smaller than that

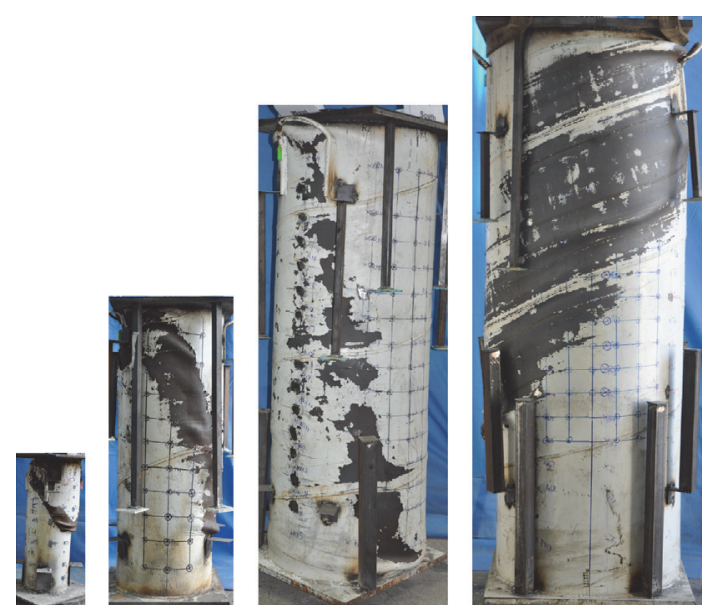

CD2-1 CD4-1

CD6-1

CD8-1

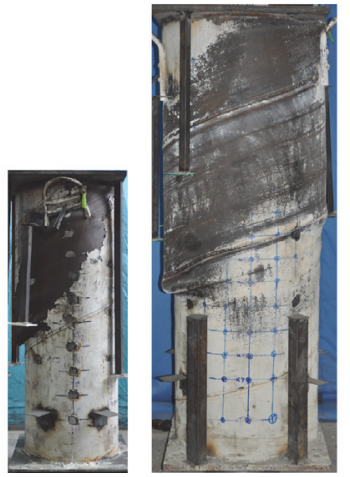

CD6-2

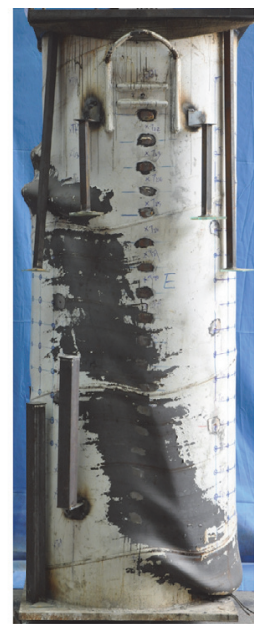

CD8-2
FIGURE 3: Final failure mode of each specimen.

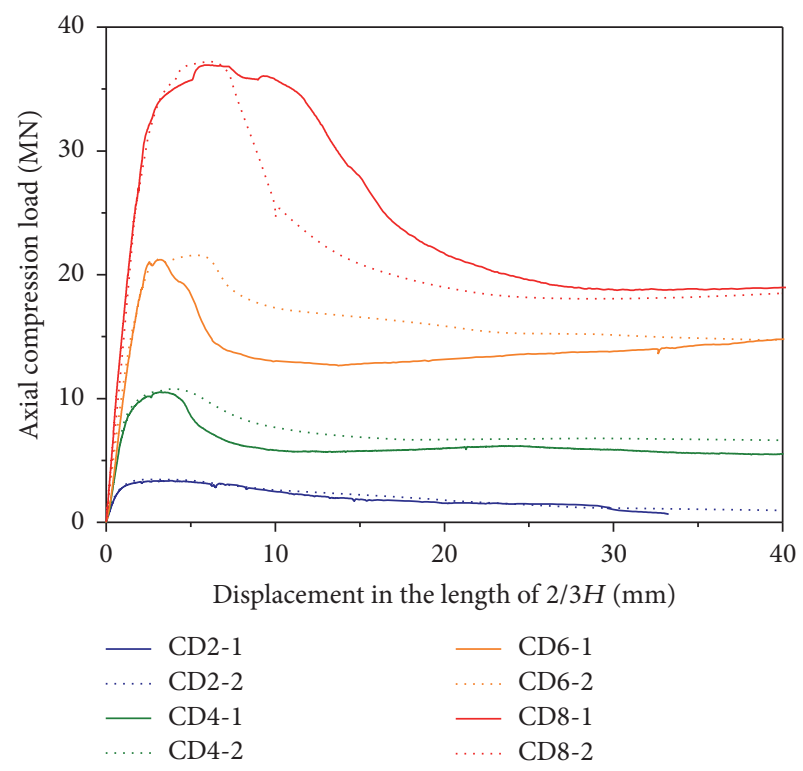

FIGURE 4: Load-deformation curves of specimens. 


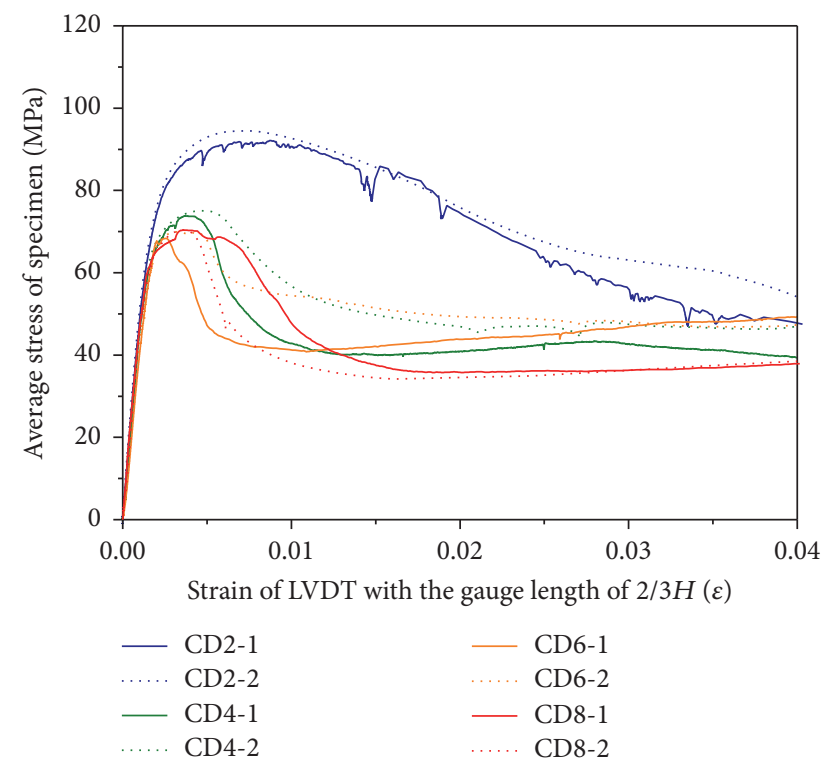

FIGURE 5: Average stress-strain curves of specimens.

TABLE 4: Test results at moment of peak bearing capacity for each specimen.

\begin{tabular}{lccccc}
\hline $\begin{array}{l}\text { Specimen } \\
\text { number }\end{array}$ & $\begin{array}{c}\text { Peak load } \\
N_{\text {exp }} \\
{[\mathrm{kN}]}\end{array}$ & $\begin{array}{c}\text { Peak } \\
\text { average } \\
\text { stress } f_{\text {cs }} \\
{[\mathrm{MPa}]}\end{array}$ & $\begin{array}{c}\text { Stress of } \\
\text { confined } \\
\text { concrete } \\
f_{\text {cc_exp }} \\
{[\mathrm{MPa}]}\end{array}$ & $N_{\exp } / N_{u}$ & $\begin{array}{c}\text { Average of } \\
N_{\text {exp }} / N_{u}\end{array}$ \\
\hline CD2-1 & 3357 & 92.12 & 78.35 & 0.96 & 0.98 \\
CD2-2 & 3483 & 94.52 & 83.98 & 1.00 & \\
\hline CD4-1 & 10523 & 73.90 & 68.85 & 1.02 & 1.03 \\
CD4-2 & 10784 & 75.26 & 71.11 & 1.04 & \\
\hline CD6-1 & 21207 & 68.35 & 62.06 & 0.98 & 0.98 \\
CD6-2 & 21582 & 69.68 & 63.58 & 0.99 & 1.01 \\
\hline CD8-1 & 36933 & 70.38 & 64.80 & 1.02 & \\
CD8-2 & 37221 & 70.34 & 65.61 & 1.01 & \\
\hline
\end{tabular}

of the steel tube, so the core concrete and the steel tube are axially compressed independently. As the load increases, the axial deformation becomes large enough that the hoop deformation of the core concrete exceeds that of the steel tube. This occurs at the mean time of hoop tensile stress development in the steel tube, when it deforms with the expansion of the core concrete. Hence, the hoop stress in the steel tube exerts a confinement stress to concrete core. This subjects the core to triaxial compression, whereas the steel tube experiences vertical compression and lateral hoop tension (the radial stress of the steel tube is small enough to be neglected). The two-way stress in tension and compression of the steel tube obeys the Von Mises yield criterion; therefore, the longitudinal stress decreases and the hoop stress increases when the equivalent stress of the steel tube reaches the yield strength $f_{y}$ of the steel. Thus, the interaction between the steel tube and concrete improves the axial bearing capacity of the specimen.

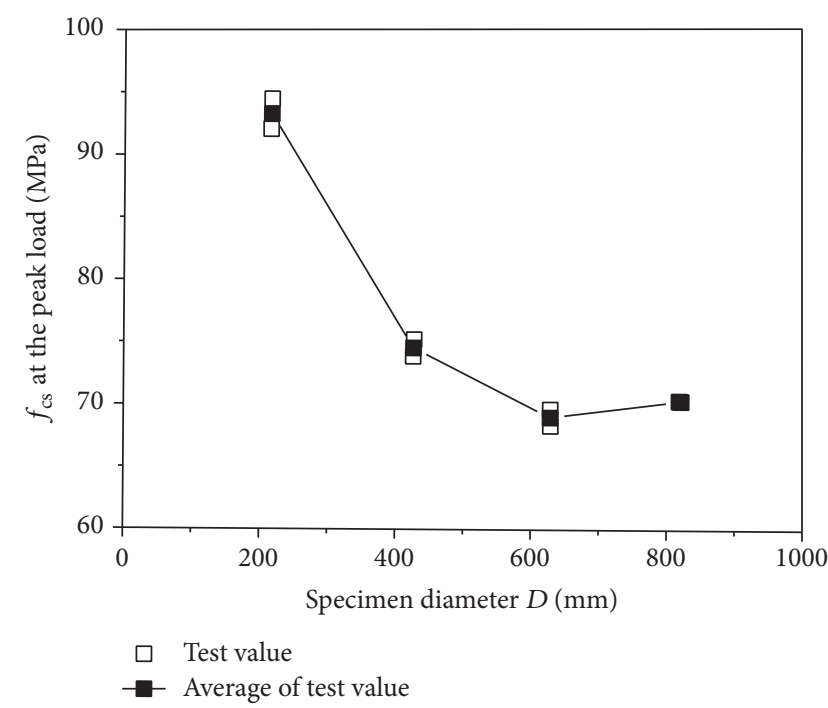

FIGURE 6: Relationship between peak average stress and size of specimen.

Concrete is intrinsically affected by size because of the quasi-brittle and anisotropic nature of the material. The steel tube is not influenced by size unless it is deformed with concrete, because deformation can affect the tube's two-way stress in tension and compression. Thus, in addition to considering the size effect on the strength of concrete, the axial bearing capacity of the circular CFT must also be analyzed to determine whether size affects the stress in the steel tube, as this is related to the improvement in strength the tube provides through confinement.

From the above analysis, a size-dependent model for predicting the axial compressive bearing capacity of a circular CFT was established as

$$
\begin{aligned}
N_{u} & =A_{s} f_{s z}+A_{c} f_{c c}, \\
f_{c c} & =f_{c D}+K f_{r}, \\
f_{r} & =\frac{-2 t}{D-2 t} f_{s \theta}, \\
f_{s \theta} & =G_{\theta} f_{y}, \\
f_{s z} & =-G_{z} f_{y},
\end{aligned}
$$

where $N_{u}$ is the computed axial bearing capacity of the circular CFT $(\mathrm{kN}), A_{s}$ is the cross-sectional area of the steel tube $\left(\mathrm{mm}^{2}\right), A_{c}$ is the cross-sectional area of the concrete $\left(\mathrm{mm}^{2}\right)$, $f_{c c}$ is the strength of the confined concrete at the moment of peak bearing capacity $(\mathrm{MPa}), f_{c D}$ is the size-dependent compressive strength of the concrete cylinder $(\mathrm{MPa}), f_{r}$ is the confining stress provided by the steel tube at the moment of peak bearing capacity (MPa), $K$ is the coefficient of confinement strength under triaxial compression, $f_{s \theta}$ is the hoop stress in the steel tube when the peak load is achieved (MPa), $f_{s z}$ is the vertical stress in the steel tube at peak load $(\mathrm{MPa})$, and $G_{\theta}$ and $G_{z}$ are the hoop and vertical stress factors, respectively, for the steel tube at peak load. The variables $f_{c D}$, 


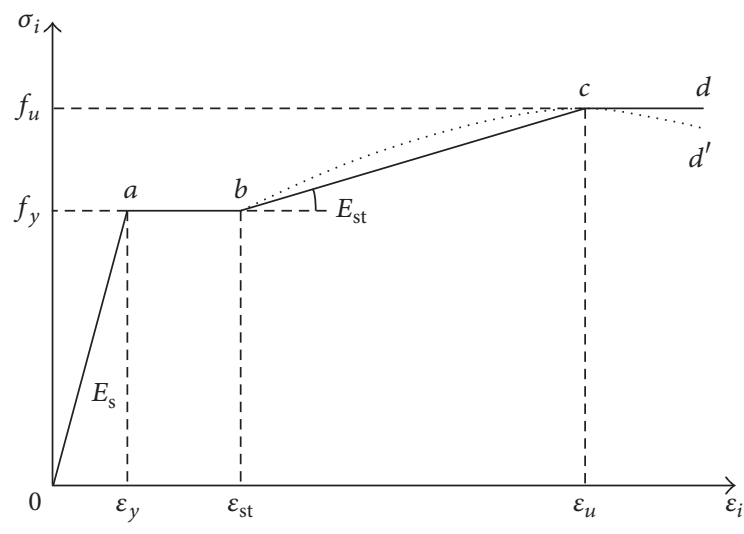

FIGURE 7: Constitutive relationship of equivalent stress-strain of steel tube.

$G_{\theta}$, and $G_{z}$ are all related to the specimen size, and $K$ varies with $G_{\theta}$. A detailed analysis of each parameter is provided in Sections 4.2 to 4.4 .

4.2. Size Effect on the Steel Tube Stress. To obtain $G_{\theta}$ and $G_{z}$, it was necessary to convert the measured strain of the steel tube into the stress of the steel tube using the model developed by $\mathrm{Gu}$ [27], which conforms to the Von Mises yield criterion. Using this method, the component stress of the steel tube obeys a generalized form of Hooke's law in the elastic stage of equivalent stress, while the initial value in the plastic stage is acquired through total deformation theory and the numerical iterative method. Incremental theory was utilized within the plastic stage of equivalent stress, with differential equations based on the Prandtl-Lester flow rule and the Von Mises yield criterion being solved simultaneously to obtain the hoop and longitudinal stress components of the steel tube.

The equivalent stress-strain curve for the steel tube obtained using Gu's [27] model is displayed in Figure 7. Here, the elastic modulus of steel is set at $E_{s}=206000 \mathrm{MPa}$, and Poisson's ratio in the elastic region is 0.283 . The end strain of the plastic platform $\varepsilon_{\text {st }}$, the corresponding strain for the ultimate strength of steel $\varepsilon_{u}$, and the stiffness in the plastic intensive stage $E_{\mathrm{st}}$ all represent averages taken from the corresponding material characterization test results for the steel tube. Figure 8 shows the constitutive relationship between the equivalent stress, hoop stress, and vertical stress versus the vertical strain of the steel tube, as measured at gauge points $G$ 1 and G-2 on specimen CD4-2. The red line in Figure 8 indicates the moment of peak bearing capacity and so demonstrates that, at these gauge points, the equivalent stress of the steel tube is in the plastic deformation stage at the moment of peak bearing capacity.

It is shown in Figure 2 that, at the moment of peak load, all specimens mainly experience axial deformation. The mean values for the hoop and vertical stress at all gauge points on the specimen at this moment $\left(f_{s \theta_{-} \text {exp }}, f_{s z_{-} \text {exp }}\right)$ are therefore regarded as the representative hoop and longitudinal stresses of the steel tube. With specimen CD4-2 as an example, the hoop and vertical stresses at all gauge points are listed

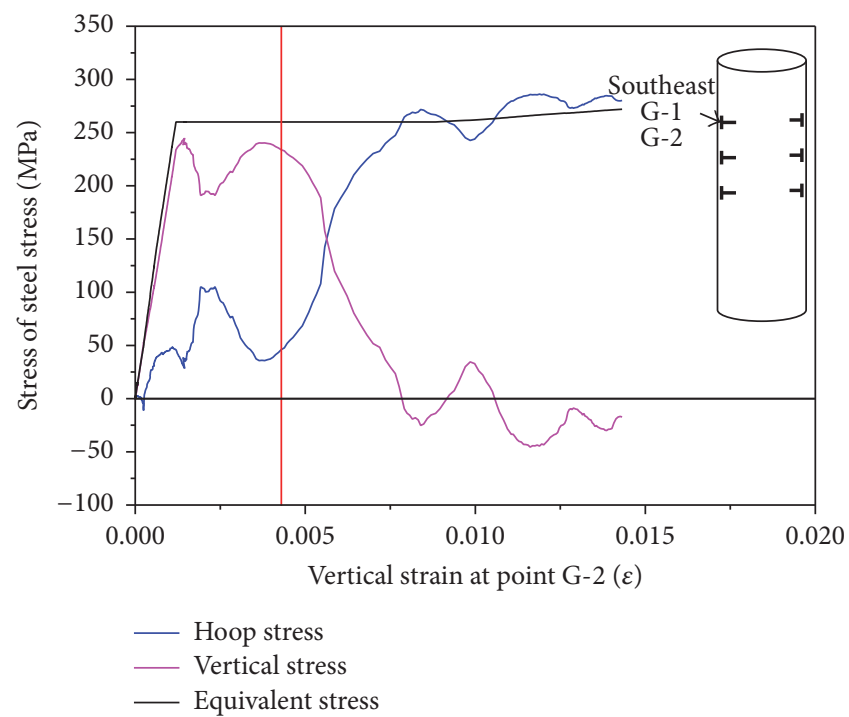

FIGURE 8: Stress-strain relationship of steel tube at gauge points G-1 and G-2.

TABLE 5: Stresses of steel tube in specimen CD4-2.

\begin{tabular}{lccc}
\hline $\begin{array}{l}\text { Number of } \\
\text { gauge points }\end{array}$ & $\begin{array}{c}\text { Hoop stress of } \\
\text { steel tube/MPa }\end{array}$ & $\begin{array}{c}\text { Longitudinal } \\
\text { stress of steel } \\
\text { tube/MPa }\end{array}$ & $\begin{array}{c}\text { Equivalent } \\
\text { stress of steel } \\
\text { tube/MPa }\end{array}$ \\
\hline G-1, 2 & 46 & -234 & 260 \\
G-3, 4 & 114 & -183 & 260 \\
G-5, 6 & 8 & -256 & 260 \\
G-7, 8 & 147 & -154 & 260 \\
G-9, 10 & 166 & -134 & 260 \\
G-11, 12 & 132 & -168 & 260 \\
G-13, 14 & 121 & -177 & 260 \\
G-15, 16 & 214 & -75 & 260 \\
G-17, 18 & 149 & -151 & 260 \\
G-19, 20 & 212 & -79 & 260 \\
G-21, 22 & 173 & -126 & 260 \\
G-23, 24 & 127 & -173 & 260 \\
\hline Average & 134 & -159 & 260 \\
\hline
\end{tabular}

in Table 5, and $f_{s \theta_{-} \exp }$ and $f_{s z_{-} \exp }$ are 134 and $-159 \mathrm{MPa}$, respectively.

This allowed the experimental hoop and vertical stress factors for the steel tube $\left(G_{\theta_{-} \text {exp }}, G_{z_{-} \text {exp }}\right)$ to be acquired by (3), as shown in Table 6 and Figure 9. Note that the stress factor of the steel tube is independent of its yield strength. Also evident in Figure 9 is that, at the peak load moment, the hoop stress factor of the steel tube $G_{\theta_{-} \text {exp }}$ is reduced with increasing specimen diameter, but the vertical stress factor $G_{z_{-} \text {exp }}$ is gradually increased. Furthermore, the component stress factor plateaus when the specimen diameter is increased beyond $630 \mathrm{~mm}$. 
TABLE 6: Stress factors of steel tube at peak load.

\begin{tabular}{lcccc}
\hline $\begin{array}{l}\text { Specimen } \\
\text { number }\end{array}$ & $G_{\theta_{-} \exp }$ & $\begin{array}{c}\text { Average of } \\
G_{\theta_{-} \exp }\end{array}$ & $G_{z_{-} \exp }$ & $\begin{array}{c}\text { Average of } \\
G_{z_{-} \exp }\end{array}$ \\
\hline CD2-1 & $57.2 \%$ & $60.7 \%$ & $63.5 \%$ & $58.4 \%$ \\
CD2-2 & $64.1 \%$ & & $53.4 \%$ & \\
\hline CD4-1 & $45.0 \%$ & $48.3 \%$ & $67.0 \%$ & $64.1 \%$ \\
CD4-2 & $51.5 \%$ & & $61.2 \%$ & \\
\hline CD6-1 & $37.1 \%$ & $38.4 \%$ & $75.0 \%$ & $73.6 \%$ \\
CD6-2 & $39.6 \%$ & & $72.3 \%$ & \\
\hline CD8-1 & $43.8 \%$ & $45.9 \%$ & $69.2 \%$ & $65.2 \%$ \\
CD8-2 & $48.0 \%$ & & $61.2 \%$ & \\
\hline
\end{tabular}

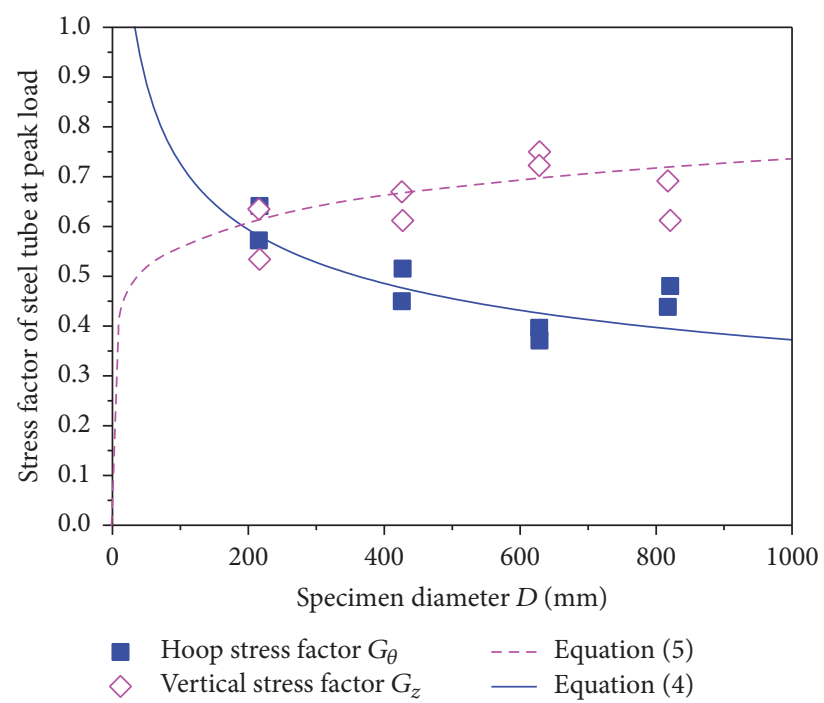

FIGURE 9: Relationship between stress factors of steel tube and specimen size at moment of peak load.

By fitting the data in Figure 9, a component stress factor for the steel tube that considers the effect of specimen size at the moment of peak load can be estimated by

$$
\begin{aligned}
& G_{\theta}=2.76 D^{-0.29}, \\
& G_{z}=0.32 D^{0.12} .
\end{aligned}
$$

4.3. Size Effect on the Stress of Confined Concrete at Peak Load. The experimental strength of the confined concrete when peak bearing capacity is reached $\left(f_{\mathrm{cc}_{-} \exp }\right)$ can be obtained by substituting the known test values $\left(N_{\exp }\right.$ and $f_{\text {cc_exp }}$ in lieu of $N_{u}$ and $f_{s z}$ ) into (1), the results of which are listed in Table 4. The relationship between $f_{\text {cc_exp }}$ and specimen size presented in Figure 10 indicates that, at the moment of the peak load, the strength of the confined concrete decreases with increasing specimen diameter. However, this decrease is stabilized when the specimen diameter is greater than $630 \mathrm{~mm}$. The concaveupward trend in Figure 10 is caused by the slight increase of the hoop stress in the steel tube, while the longitudinal stress in steel tube is slightly decreased at the peak load when the diameter exceeds $630 \mathrm{~mm}$, as shown in Figure 9. Hence, the

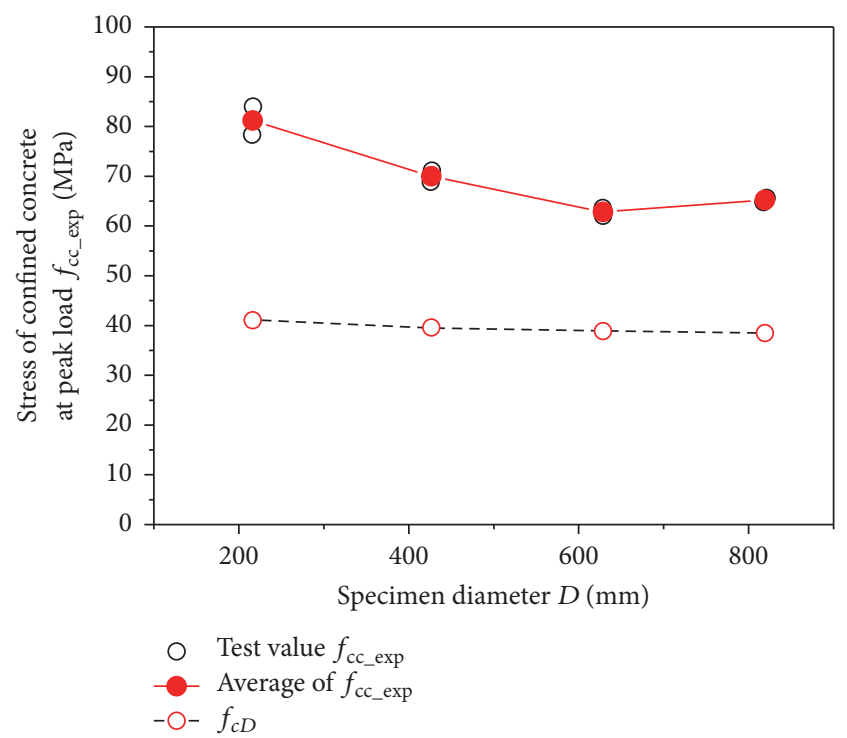

FIGURE 10: Relationship between strength of confined concrete and specimen size at moment of peak load.

vertical capacity of the steel tube decreases, while the axial capacity of the core concrete increases, which leads to the concave feature in Figure 10.

The effect of specimen size on the strength of the confined concrete can be analyzed in terms of both the strength of the concrete itself and the improvement in strength provided by the confinement of the steel tube. The former can be reflected by a size effect reduction factor $R$ applied to the strength of a concrete cylinder. Considering the influence of the various test factors and the amount of test data, Kim et al's formula [8] was adopted to estimate $R$, as expressed in (6). A shape conversion factor is also needed for the compressive strength of concrete, to translate the data obtained with a $150 \times 150 \times$ $300 \mathrm{~mm}$ prism to a $150 \times 300 \mathrm{~mm}$ cylinder. Based on the recommendations of the American Concrete Institute mentioned in the literature [28], the shape conversion factor selected is 1.073. The value of $f_{c D}$ is therefore given by (7):

$$
\begin{aligned}
R & =\frac{0.4}{[1+(H-D) / 50]^{0.5}+0.8}, \\
f_{c D} & =1.073 R f_{c} .
\end{aligned}
$$

The model established in this study is based on the premise of the cylinder strength of concrete with the diameter of $150 \mathrm{~mm}$, using the size effect reduction model ((6)-(7)) to verify the cylinder strength of concrete $\left(f_{c D}\right)$ in steel tubes of different diameters.

Since Section 4.2 revealed that the hoop stress factor of the steel tube decreases with increasing specimen diameter, the confining stress $\left(f_{r}\right)$ can be determined by (2) and (3). That is, the confinement stress on the concrete core that is provided by the steel tube weakens as the specimen becomes larger.

It is also necessary to investigate the variation in $K$ under different confining stresses. The experimental value $K_{\exp }$ was calculated by substituting the obtained test factors into (2) 


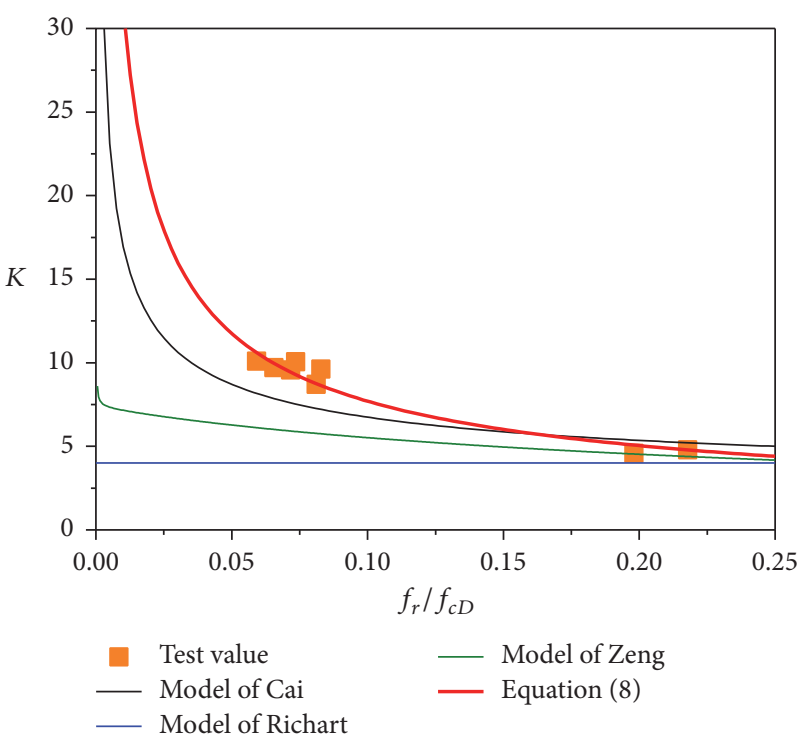

FIGURE 11: $K-f_{r} / f_{c D}$ relationship at moment of peak load.

and (3) and then compared with three commonly used $K$ models [29-31]. As shown in Figure 11, this comparison demonstrates little difference between the test data and the three models when the confining stress is large, but only Cai and Jiao's model [31] does not underestimate the improvement in strength by the confinement effect when the confining stress is small. The relation between $K_{\exp }$ and the confining stress is therefore clearly nonlinear, and so by fitting the test data in Figure 11, $K$ can be estimated as

$$
K=1.89\left(\frac{f_{r}}{f_{c D}}\right)^{-0.61}
$$

Figure 12 describes the compositional ratio of the strength of the confined concrete specimen at the moment of peak bearing capacity, based on the average of two specimens from the same group. This reveals that size has a greater effect on the improvement in strength by the confinement than on the strength of the concrete material itself.

4.4. Comparison of Experiments and Analytical Model. The above analysis demonstrates that specimen size has an effect on all three components of the axial bearing capacity of a circular CFT, that is, the strength of the concrete, the improvement in concrete strength from confinement, and the vertical stress in the steel tube. Among them, the size effect on the confinement part of the bearing capacity is the largest; namely, the confinement part decreases the most with increasing size. The size effect on the concrete strength was obtained based on existing research results. The size affects both the vertical and hoop stresses of the steel tube, and the trend of the vertical stress is opposite to that of the hoop stress.

A model for the axial bearing capacity of a circular CFT that considers the size effect can therefore be perfected by incorporating (2)-(8) into (1). This model can be applied to circular CFTs with a concrete degree of C50, a steel tube grade

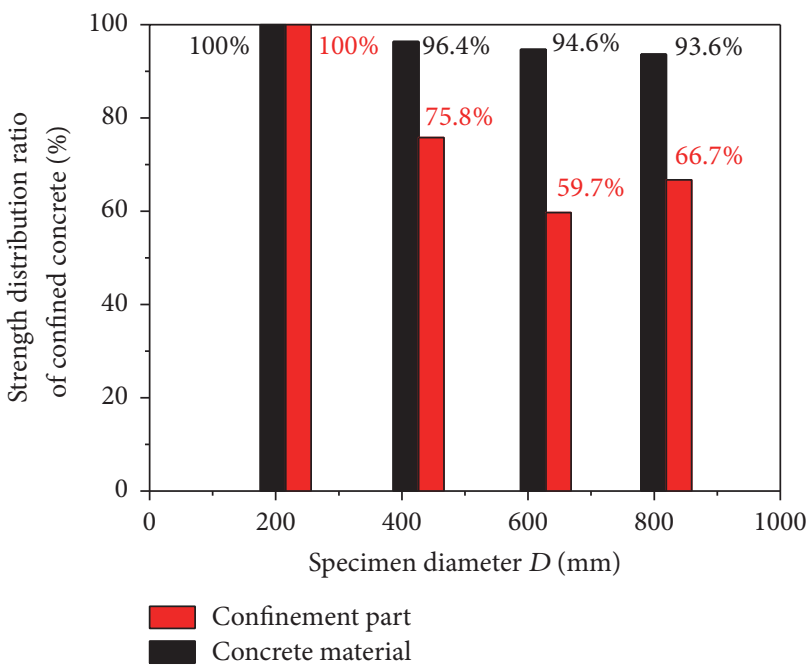

FIGURE 12: Compositional ratio of confined concrete strength.

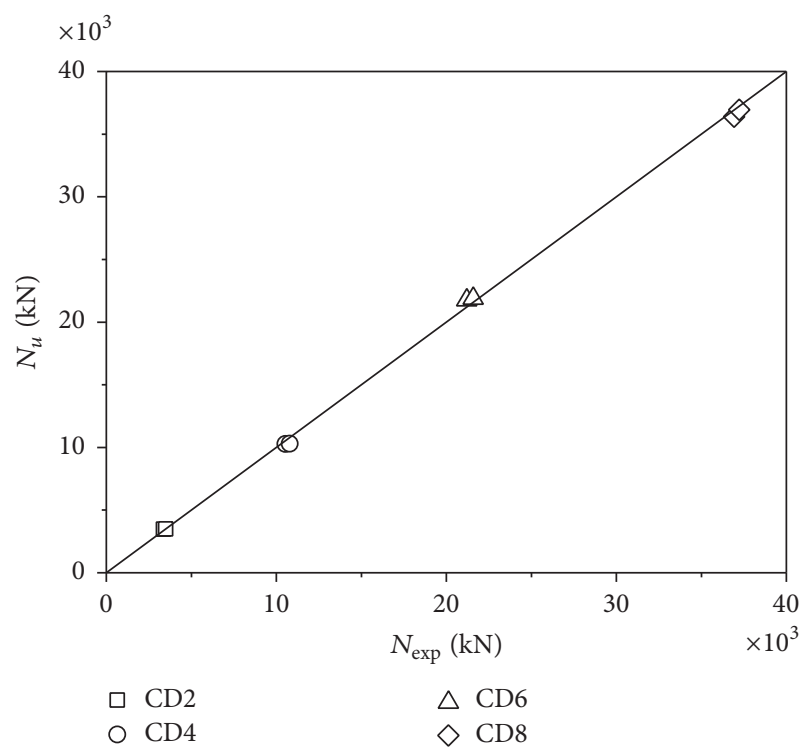

FIgURE 13: Comparison of experimental results and proposed model.

of Q235, and a $D / t$ ratio of 88 . The ratio of the experimental capacity $N_{\exp }$ to the model calculation of $N_{u}$ is listed in Table 4, and these two values are compared in Figure 13. This demonstrates that the model agrees very well with the experimental results.

It has been long doubted whether the CFT axial capacity used in design should consider the beneficial effect of concrete core confinement, because this argument was developed based on small-scale specimen investigations. The results in this study indicate that the confinement effect is weakened in large-size CFTs. Therefore, the current design formula based on research data from small-scale specimens is not accurate and unsafe to estimate the bearing capacity of large-size CFT components; that is, specimen size should be considered and used in the design. In this study, the size effect on the bearing 
capacity of a CFT under one situation $\left(D / t=88, f_{c}=\right.$ 41.24 MPa) was analyzed, to verify the existence of the size effect. A method considering the size effect was proposed to calculate the bearing capacities of CFTs. The method is proposed under one set of conditions, so further research considering other factors is necessary before the applicability and practicality of the method meet the requirements of design.

\section{Conclusions}

Experimental investigation and theoretical analysis has revealed that circular CFT columns with a $D / t$ ratio of 88 deform in a similar manner regardless of diameter within the range of $D=219-820 \mathrm{~mm}$. At the moment of peak bearing capacity, the columns primarily develop axial deformation. The peak average stress is reduced with increasing diameter but plateaus for diameters greater than $630 \mathrm{~mm}$.

The ultimate axial compressive capacity of a circular CFT column is determined by the inherent strength of the concrete, the increase in strength provided by confinement, and the vertical stress of the steel tube. With increases in the specimen diameter, the compressive strength of the concrete cylinder is decreased because of its heterogeneity, and less strengthening is provided by confinement because of the reduction in hoop stress in the steel tube. The vertical stress in the steel tube is improved with an increase in specimen diameter, meaning that each of the three components of the bearing capacity is affected differently by the size of the specimen. Among the three components, the size effect on the confinement part is the most significant.

This size effect on the three components of the axial bearing capacity of a circular CFT is reflected through an SEL that incorporates a factor for the reduction in concrete cylinder strength with size $R$, the coefficient of confinement under triaxial compression $K$, and both hoop and vertical factors for the steel tube $\left(G_{\theta}\right.$ and $\left.G_{z}\right)$. A size-dependent model, established to predict the axial bearing capacity of circular CFT using this law, has been proven to agree well with experimental results, showing the potential to provide more useful data for practical engineering applications.

\section{Competing Interests}

The authors declare that there are no competing interests related to this paper.

\section{Acknowledgments}

The research presented herein was supported by the Key Laboratory Open Fund of Urban Safety and Disaster Reduction (2013ZD02) and the National Natural Science Foundation of China (50838001).

\section{References}

[1] B. C. Gourley, C. Tort, M. D. Denavit, P. H. Schiller, and J. F. Hajjar, "A synopsis of studies of the monotonic and cyclic behavior of concrete-filled steel tube members, connections, and frames," NSEL Report Series NSEL-008, 2008.

[2] GB50936-2014, Technical Code for Concrete Filled Steel Tubular Structures, China Architecture \& Building Press, Beijing, China, 2014 (Chinese).

[3] AIJ-2008, Guide for Construction of Concrete Filled Steel Tubular Structure Design, Architectural Institute of Japan, Tokyo, Japan, 2008.

[4] ANSI/AISC 360-10, Specification for Structural Steel Buildings, American Institute of Steel Construction, Chicago, Ill, USA, 2010.

[5] R. F. Blanks and C. C. McNamara, "Mass concrete tests in large cylinders," ACI Journal Proceedings, vol. 31, pp. 280-303, 1935.

[6] T. Noguchi and F. Tomosawa, "Effect of size and shape of specimen on mechanical properties of high strength concrete in compression," Journal of Structural and Construction Engineering, Tokyo, no. 473, pp. 19-28, 1995.

[7] Z. P. Bažant and Y. Xiang, "Size effect in compression fracture: splitting crack band propagation," Journal of Engineering Mechanics, vol. 123, no. 2, pp. 162-172, 1997.

[8] J.-K. Kim, S.-T. Yi, C.-K. Park, and S.-H. Eo, "Size effect on compressive strength of plain and spirally reinforced concrete cylinders," ACI Structural Journal, vol. 96, no. 1, pp. 88-94, 1999.

[9] Z.-B. Li, J. Song, X.-L. Du, and X.-G. Yang, "Size effect of confined concrete subjected to axial compression," Journal of Central South University, vol. 21, no. 3, pp. 1217-1226, 2014.

[10] J. Song, Z. Li, Y. Wang, and Y. Zuo, "Stress-strain constitutive model of concrete confined by hoops with considering size effect," Journal of Building Structures, vol. 36, no. 8, pp. 99-107, 2015 (Chinese).

[11] Y.-F. Wang and H.-L. Wu, "Size effect of concrete short columns confined with aramid FRP jackets," Journal of Composites for Construction, vol. 15, no. 4, pp. 535-544, 2011.

[12] A. S. Elkadi and J. G. M. van Mier, "Experimental investigation of size effect in concrete fracture under multiaxial compression," International Journal of Fracture, vol. 140, no. 1-4, pp. 55-71, 2006.

[13] L. K. Luksha and A. P. Nesterovich, "Strength testing of largediameter concrete filled steel tubular members," in Proceedings of the 3rd International Conference on Steel-Concrete Composite Structures, pp. 67-72, Fukuoka, Japan, September 1991.

[14] T. Yamamoto, J. Kawaguchi, and S. Morino, "Experimental study of scale effects on the compressive behavior of short concrete-filled steel tube columns," in Proceedings of the Conference: Composite Construction in Steel and Concrete IV, pp. 879890, June 2000.

[15] Y.-J. Chen, Y. Li, W.-M. Yan, and D. Pan, "Bearing capacity test of large size concrete filled steel tubular column," China Journal of Highway and Transport, vol. 24, no. 4, pp. 33-38, 2011 (Chinese).

[16] Y. Tian, Experimental Research on Size Effect of Concrete-Filled Steel Tubular Stub Columns under Axial Compressive Load, Harbin Institute of Technology, Harbin, China, 2014 (Chinese).

[17] T. Yamamoto, J. Kawaguchi, and S. Morino, "Experimental study of the size effect on the behavior of concrete filled circular steel tube columns under axial compression, J. Struct. Constr. Eng," AIJ, vol. no. 561, pp. 237-244, 2002.

[18] T. Yamamoto, J. Kawaguchi, and S. Morino, "Experimental study on the load-deformation characteristics of concrete filled circular steel tube short columns under axial compression considering size effect," Journal of Structural and Construction Engineering (Transactions of AIJ), no. 592, pp. 193-200, 2005. 
[19] K. Sakino, H. Nakahara, S. Morino, and I. Nishiyama, "Behavior of centrally loaded concrete-filled steel-tube short columns," Journal of Structural Engineering, vol. 130, no. 2, pp. 180-188, 2004.

[20] T. Yamamoto, J. Kawaguchi, S. Morino, and S. Koike, "Experimental study on the effect of cross sectional size and shape on compressive characteristics of concrete filled square steel tube short columns," Journal of Structural and Construction Engineering, vol. 78, no. 685, pp. 597-605, 2013.

[21] Q.-Q. Liang and S. Fragomeni, "Nonlinear analysis of circular concrete-filled steel tubular short columns under axial loading," Journal of Constructional Steel Research, vol. 65, no. 12, pp. 21862196, 2009.

[22] Q.-Q. Liang, "Performance-based analysis of concrete-filled steel tubular beam-columns, part I: theory and algorithms," Journal of Constructional Steel Research, vol. 65, no. 2, pp. 363$372,2009$.

[23] F. C. Caner and Z. P. Bažant, "Lateral confinement needed to suppress softening of concrete in compression," Journal of Engineering Mechanics, vol. 128, no. 12, pp. 1304-1313, 2002.

[24] H.-L. Wu and Y.-F. Wang, "Study on size effect of concrete filled steel tubular columns," Journal of Harbin Institute of Technology, vol. 39, supplement 2, pp. 22-25, 2007 (Chinese).

[25] GB-T 228.1-2010, Metallic Materials-Tensile Testing-Part 1: Method of Test at Room Temperature, China Zhijian, Standards press of China, Beijing, China, 2010 (Chinese).

[26] GB/T 50081-2002, Standard for Test Method of Mechanical Properties on Ordinary Concrete, Architecture \& Building Press, Beijing, China, 2002 (Chinese).

[27] W.-P. Gu, "Stress analysis of concrete filled steel tubular columns," Building Science, no. 2, pp. 14-21, 1987 (Chinese).

[28] J.-P. Zhou, X.-Q. Niu, and J.-S. Jia, Design of Concrete Gravity Dams-A 20 Years Perspective, China Water \& Power Press, Beijing, China, 2008 (Chinese).

[29] F. E. Richart, A. Brandtzage, and R. L. Brown, "A study of the failure of concrete under combined compressive stresses," in Engineering Experimental Station, Bulletin no. 185, University of Illinois, Urbana, Ill, USA, 1928.

[30] S.-J. Zeng, X.-D. Ren, and J. Li, “Triaxial behavior of concrete subjected to dynamic compression," Journal of Structural Engineering, vol. 139, no. 9, pp. 1582-1592, 2013.

[31] S.-H. Cai and Z.-S. Jiao, "Behavior and ultimate strength of short conerere-filled steel tubular columns," Journal of Building Structures, vol. 5, no. 6, pp. 13-29, 1984 (Chinese). 

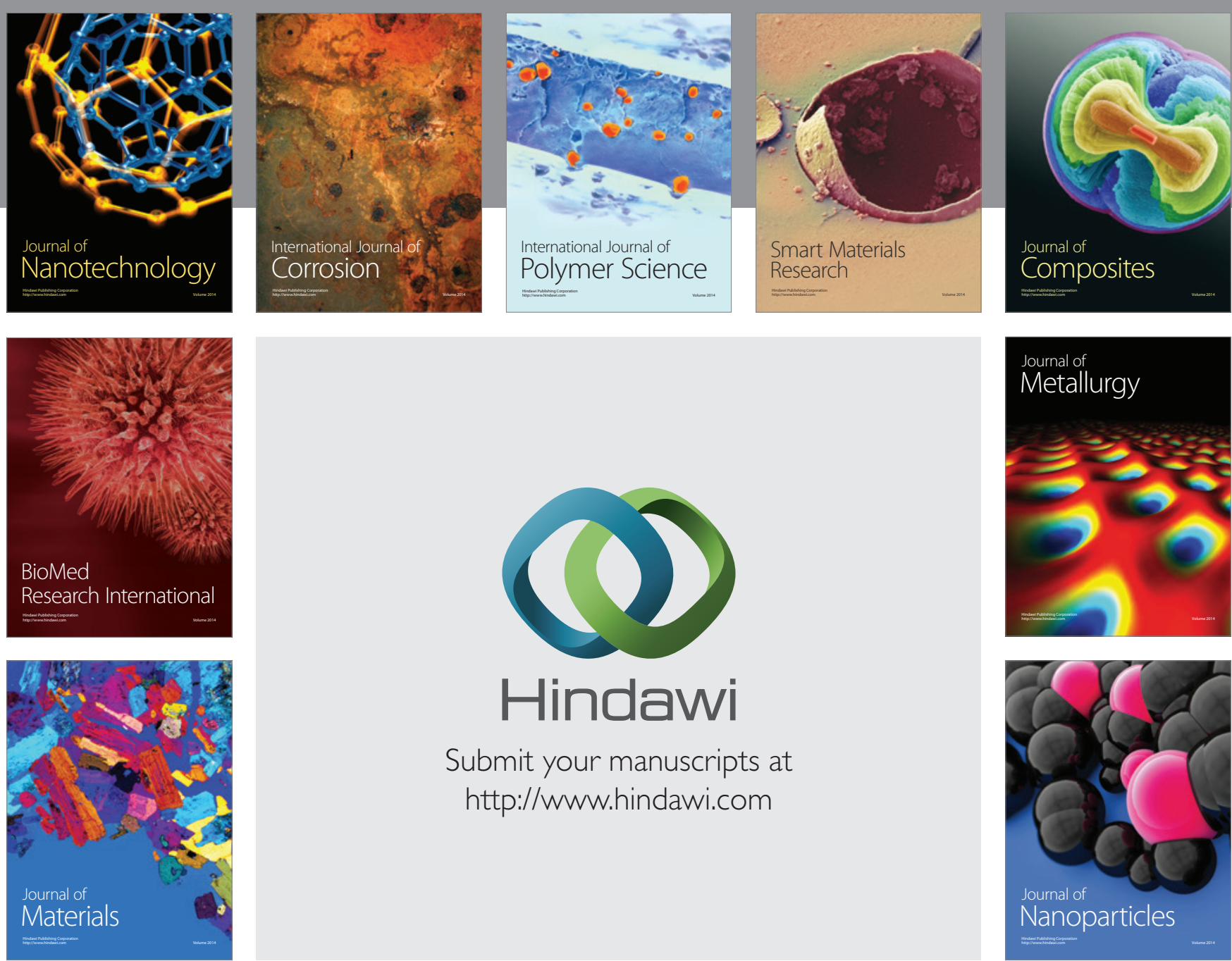

\section{Hindawi}

Submit your manuscripts at

http://www.hindawi.com

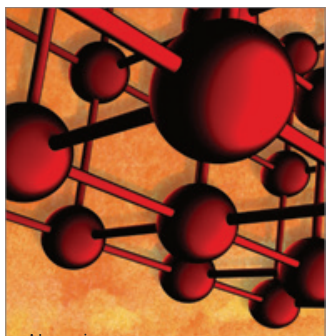

Materials Science and Engineering
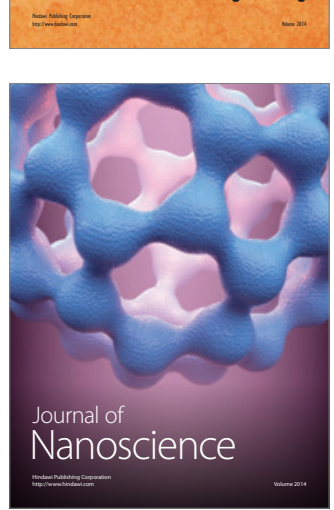
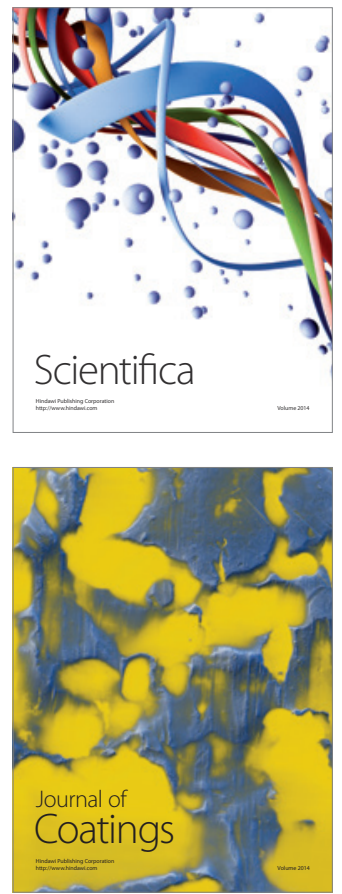
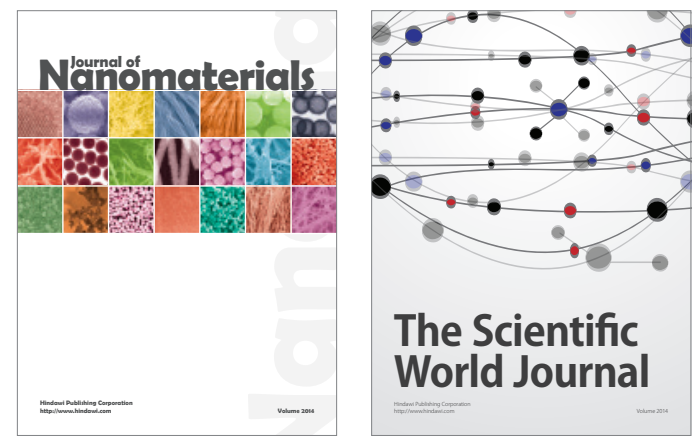

The Scientific World Journal
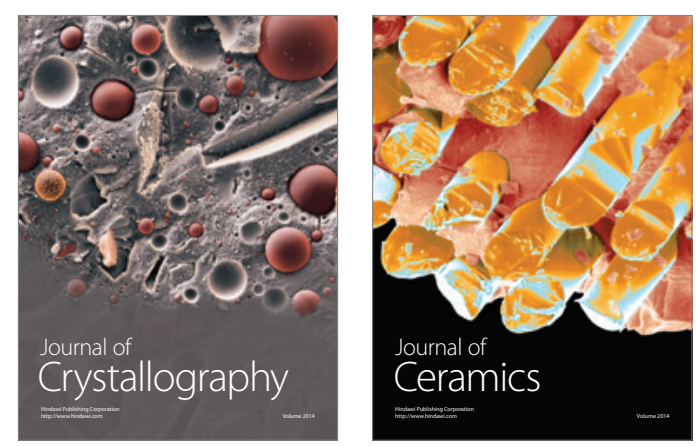
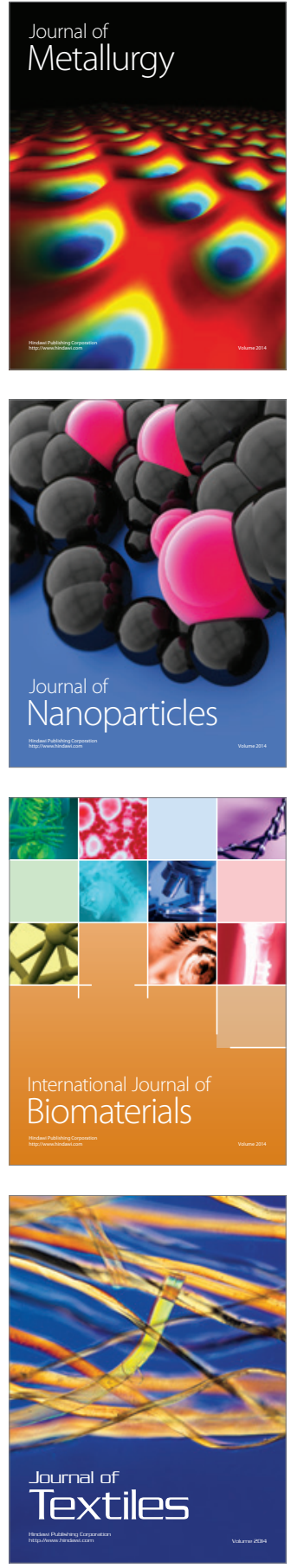